\title{
Plastic Microbeads
}

\author{
Meena.M $\mathrm{M}^{\# 1}$, Vijayalakshmi $\mathrm{A}^{* 2}$

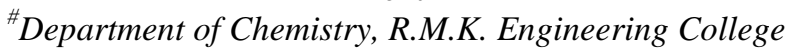 \\ ${ }^{1} \mathrm{~mm}$.shermkec.ac.in \\ avl.shermkec.ac.in
}

\begin{abstract}
Introduction of microbeads as exfoliating agents in the personal care products by replacing natural abrasives has brought devastating changes in our environment. These fragments, which impart feel good factor in the cosmetic toiletries, because of their size and shape cannot be retained by any filter mechanisms in the water treatment facilities and finds path way directly into the water stream. As the cosmetic products are increasing day by day, commercial usage of microbeads also equally increasing, which in turn upsurges the inflow level of microbeads into the drains. These microbeads are finally and intentionally released into the marine environment. The ingestion of these microbeads by zooplanktons may reach to the highest tropic level through bioaccumulation. The negative impact of microbeads on marine life is an alarming signal for other mammals.
\end{abstract}

Keywords — Microplastics, Microbeads, Ingestion, Bioaccumulation, Exfoliating agents

\section{INTRODUCTION}

"Bend me, shape me any way you want me". The lyrics of this song well suits the definition of a plastic. The basic component of plastic is, a synthetic or semisynthetic organic polymer [1]. These polymers along with different type of additives makes a plastic. These plastics have become integral part of our life. It has innumerable uses, because of its unique properties and also finds applications in all sorts of industries starting from Automotive, Industrial machinery, Medical devices, Building construction, Electrical and electronics, Consumer Goods, Packaging to Optical media [2]. But the material, which has become a part and parcel of our life is causing threat to human kind as well as all the living beings on the earth, because of its non-biodegradability. It has been estimated that, from 2008 to 2015, an increase of $23 \%$ in the production of waste, especially from packaging sector [3]. All the plastic wastes that originates from domestic or industries or through other activities ends up on land. These find their ultimate destination into sea or ocean through wind or rain [4] because of the improper waste disposal methods and practices. The appearance of plastic particles likes spherules of translucent to clear polystyrene, opaque to translucent polyethylene discs, pieces of styrofoam, sheets of thin and flexible wrapping materials on the surface waters of North Western Atlantic was reported [5] in 1974. Primary micro plastics [fragments less than $5 \mathrm{~mm}$ ] and secondary micro plastics which originate from breakdown of primary due to environmental conditions are major threat to biodiversity. The micro plastics exits as microfibers, microbeads and plastic pellets. The first report on harmfulness of microbeads [6], in personal care products to the environment was published in 1991. Two samples were analysed in the study, and it was confirmed that, the presence of polystyrene plastic particle in water bodies along with surfactants. These studies triggered the interest of the authors to elucidate the present status of the microbeads in the cosmetics world. This paper highlights the origin, implications of microbeads as well as steps taken for minimizing the same.

\section{HISTORY OF MICROBEADS}

Microbeads were invented by a chemical engineer, John Ugelstad, professor of Norwegian Institute of Technology (NIT) and a consultant of Dupont. During his tenure at NIT, he succeeded in producing monodisperse spheres. These microbeads exhibit large surface area per volume. It was a breakthrough in the polymer industry and after that, a revolution took place in the usage of microbeads. As per, UNEP (United Nations Environment Programme) microbeads were introduced, 50 year ago into personal care products. Microbeads are solid plastic particles which are less than one millimetre in size are manufactured and added to personal care products such as soap, facial scrub and toothpaste as exfoliating agents (e.g. Fig. 1 and 2) mainly to remove dead cells from the skin. But these products have replaced our traditionally used natural exfoliating agents like ground almonds, oatmeal, and pumice [7]. Commonly used synthetic microbeads are polyethylene (PE), polypropylene (PPE) and polymethylmethacrylate (PMMA).

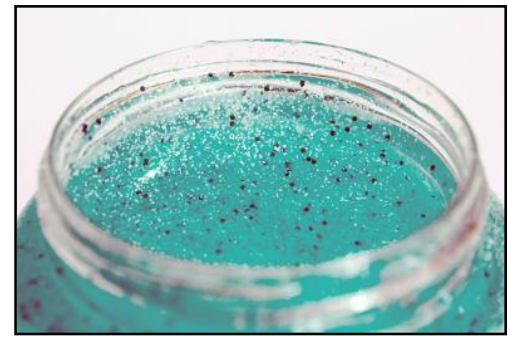

Fig. 1 Microbeads in facial gel

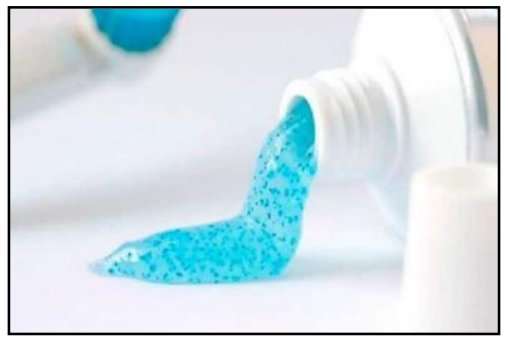

Fig. 1 Microbeads in tooth paste 
Though the patents on microbeads in personal care products started in the later years of 1960, commercial introduction started only from 1990s because they act as bulking agents, exfoliants, as a tooth polisher and apart from that, the incorporation into cosmetics, improves the shelf life by absorbing degradable ingredients [8]. But prior to this, only natural abrasive materials had been used in these products, which are biodegradable in nature.

\section{MICROBEADS IN ENVIRONMENT}

Based on the method of synthesis and chemical composition, microbeads may vary in size, shape and density. Based on the properties, these may be physically and chemically either stable or unstable. Stability is fixed to these microplastics based on the application. But most dangerous and unfriendly is stable microbeads because of its persistence in the environment. As these microbeads are too small, they end up in ocean as waste water plants cannot filter them off. Once they are released into the water stream, they may undergo physical transformation and either they may adsorb/desorb with other pollutants present [9, 10]. Based on the density and physical transformation either they may float or settle down in due course. If these are present on the surface, they may be available to pelagic and avian species or else if they settle down at the bottom, will be available for aquatic benthic species. Plastic microbeads resemble fish eggs and are often eaten by jellyfish, egg-eating fish and filter feeders. Seabirds that skim the ocean surface while flying, such as albatrosses, cannot differentiate floating food from litter.

Microplastic contamination was reported [11] in 201 edible animal species, some food products like sea salt, sugar, honey as well as beer and water. Recent report confirmed the presence of microplastics [12] in drinking water in the selected samples. But most of them were in the form of fibers and few were white to transparent and very few were coloured. But it has been mentioned that, the origin for these plastics may be very difficult to find however the source may be through supply pipelines. Another report [13] stated that, presence of more than 330000 plastic microbeads in a tube of facial scrub. When these enter into water stream, they attract persistant organic pollutants and pollute the water. It had been confirmed that the presence of microplastics in the guts of fishes sold in California market. State University of New York at Fredonia conducted a study on 259 water bottles of 11 brands from nine countries like US, China, Brazil, India, Indonesia, Mexico, Lebanon, Kenya and Thailand and revealed that, [14] that $93 \%$ of bottled water contains microplastics. It was stated that nearly 10 plastic particles were present per liter of water and each of them were larger than the width of human hair. A study on free drinking water fountains of 42 metro stations was done in Mexico city [15]. All the collected samples, exhibited the presence of fibers and few fragments of varying size and shape in the drinking water. Moreover the surface morphological studies confirmed that, they had undergone environmental weathering process.

\section{IMPLICATIONS OF MICROBEADS}

The microbeads are mistaken for fish eggs and are eaten by marine invertebrates, such as copepods, arrow worms, jellyfish, amphipods, marine snails and thus enter into various tropic levels of food chains and bioaccumulation takes place from tropic level to another. Apart from that, these microplastics may absorb toxic chemicals linked with various diseases and thus through ingestion, these chemicals may be released into fish and other mammals [16]. An interesting study was done by the researchers of UK on the ingestion of microplastics by zooplankton [17]. It was found that, these microplastics are ingested and egested, but prolonged retention time may pose risk and limit their functions and it may be transferred to other tropic level. But the consequences of these microbeads on higher vertebrate through food and water are yet to be revealed. The studies confirm that there is a possibility of all these fragments, ending up in our dinner plate through food chain. The same has been represented in Fig.3

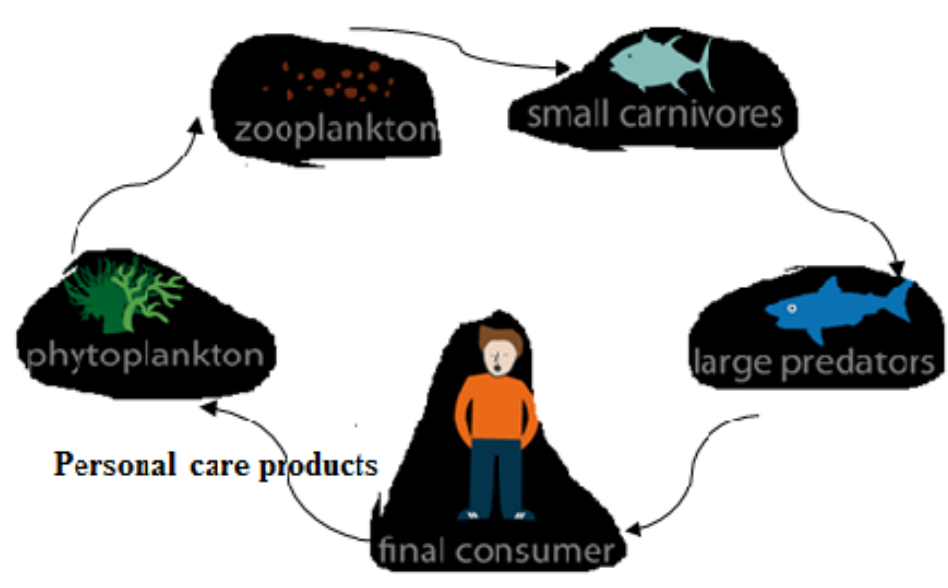

Fig. 3 Flow chain of microbeads

Hence awareness has been initiated and raised by many organisations globally which in turn resulted in banning of usage of unfilterable microbeads as exfoliating agents. Many countries like Canada, USA, Sweden, France, UK, Scotland, Netherlands, Wales, South Korea, Taiwan, New Zealand, Northern Ireland and Australia also implemented laws and banned them in cosmetic 
toiletries. Even China, the largest producer of plastic, has also planned to ban the microbeads in the cosmetic industries by the end of 2020 .

Apart from this, many corporates for example, SaSa - a leading cosmetics retailing group in Asia [18], has committed not to use any exfoliating agents in their formulations. Nearly 448 cosmetic brands have accepted to stop the usage of microbeads through a campaign called "Beat the Micobead" by Plastic soup foundation. UNEA also driven the "Clean Seas Campaign" in 2017 to tackle single use plastics as well as microbeads. Now it is in the second phase of campaign and taking efforts to address specific marine litter. It also developed an app -"Beat the Micobead" [19], which works in seven languages, so that customers can check whether their personal care products contain microbeads by scanning the barcode of the products. It also convinced many large multinational corporate like Unilever, Johnson \& Johnson and the Body Shop to announce their commitment to stop using microbeads.

\section{CONCLUSION}

The size, shape and the properties of microbeads are posing major threat to marine environment. The consequences on human being by these microbeads are yet to be known. Researchers have reviewed and published valuable reports on negative impacts of microplastics on marine biodiversity. United Nation Environment Program has raised awareness on the effects of microbeads, which was eye opener for Microbead Free Waters Act -2015 by the US government. Apart from US, many countries implemented the ban for the use of microbeads in personal care products. Initiatives have been taken by many NGOs in raising awareness campaign on the ill effects of plastics and microplastics. It is also the responsibility of corporates to minimize the usage or banning the microbeads, and as an alternative, natural and biodegradable particles can be introduced. At the same time, responsibility lies on the end user also. Only with the combined effort, it is possible to save our marine biodiversity as well as our future generation.

[1] https://www.plasticseurope.org/en/about-plastics/what-are-plastics

[2] https://www.grandviewresearch.com/industry-analysis/plastic-compounding-market

[3] Plastic Waste in the Environment, European Commission (DG Environment), 2011

[4] https://asiancorrespondent.com/2016/01/reducing-plastic-waste-should-be-a-priority-in-asia/

[5] J.L. Conkle, C. D. Báez Del Valle, and J.W. Turner, "Are We Underestimating Microplastic Contamination in Aquatic Environments?," Environmental Management, 2018, 61, p. 1.

[6] V.Zitko, M. Hanlon, "Another source of pollution by plastics: skin cleaners with plastic scrubbers," Mar. Pollut. Bull., 2017, 22 , p. 41.

[7] http://osof.org/proposal-ban-sale-manufacture-plastic-microbeads-personal-care-products-new-zealand/

[8] https://www.ijc.org/en/history-and-evolution-microbead

[9] P. Möhlenkamp, A. Purser, and L. Thomsen, "Plastic microbeads from cosmetic products: an experimental study of their hydrodynamic behaviour, vertical transport and resuspension in phytoplankton and sediment aggregates, Elem Sci Anth, 2018, p.6

[10] Microbeads - a science summary - Canada. Environment Canada- eBook : Document : National government publication

[11] Brigitte Toussaint, Barbara Raffael, Alexandre Angers-Loustau, Douglas Gilliland, Vikram Kestens, Mauro Petrillo, Iria M. Rio-Echevarria \& Guy Van den Eede,"Review of micro- and nanoplastic contamination in the food chain," Food Additives \& Contaminants: Part A, 2019, p.1

[12] Analysis of microplastic particles in danish drinking water, Danish Centre for Environment and Energy, No. 291, 2018

[13] https://www.5gyres.org/microbeads

[14] ] https://www.fredonia.edu/news/professors-research-bottled-water-achieves-worldwide-audience

[15] V.C. Shruti, F. Pérez-Guevara, G. Kutralam-Muniasamy, Metro station free drinking water fountain- A potential "microplastics hotspot" for human consumption, Environmental Pollution ,2020, in pre proof.

[16] https://www.downtoearth.org.in/news/water/you-may-be-drinking-tiny-pieces-of-plastic-with-bottled-water-59929

[17] Matthew Cole, Pennie Lindeque, Elaine Fileman, Claudia Halsband, Rhys Goodhead, Julian Moger, and S. Tamara Galloway, "Microplastic Ingestion by Zooplankton,” Environ. Sci. Technol. 2013, 47, p. 6646

[18] http://corp.sasa.com/en/corporate-governance/environment-social-and-corporate-governance-policy-statement/

[19] https://news.un.org/en/story/2015/06/501822-un-environment-agency-urges-ban-microplastics-cosmetics-and-personal-care 